\title{
The Effect of Claim Settlement on Profit Maximization in the Insurance Industry
}

\author{
Author: Kayode Ogunlami \\ Department of Insurance \\ School of Management and Business Studies \\ Lagos State Polytechnic, Ikorodu. \\ $+2348023450306$ \\ DOI: 10.26821/IJSRC.9.9.2021.9612
}

\begin{abstract}
The decline in the performance of insurance firms due to improper management of information relating claims calls for the attention of researchers. This paper hereby examines the effect of claim settlement on profit maximization in the insurance industry. The objectives of this paper are to determine whether claim handling has effect on profit maximization in an insurance company, and to ascertain whether claim's information systems are always well-designed for proper identification of existing policies by insurance companies. The research method and design adopted for this research work is the survey design method. Ordinary Regression Model was used to test the hypotheses formulated for this study. This paper revealed that claim handling has significant effect on profit maximization of an insurance company; and claim's information systems that are well-designed results to proper identification of existing policies by insurance companies. This paper hereby recommended that claims managers in the Nigerian insurance industry must effectively manage their claims processes, in order to reduce the number of claims for every earned premium; a careful attention must also be given to other administrative cost, such as the underwriting cost, which is capable of reducing the company's profit margin. Future studies can consider the effect of the explanatory variables on other measures of profitability; Nigerian insurance companies should pay special attention to their underwriting process and examine critically the sources and development of new and old businesses; and the industry should disaggregate return distributions across the different classes of insurance so as to ensure competitive strategies.
\end{abstract}

Keywords: Claim Settlement, Profit Maximization, Insurance Industry, Underwriting Cost

\section{Introduction}

Insurance companies sell promises to people, in form of policies. This is a promise to indemnify or bring a policyholder back to his original financial position, prior to the occurrence of a loss. An insurance policy is therefore a promise by the insurer to the policyholder to pay for future claims, while receiving the premium 
upfront. The settlement of claims is the prime objective of insurance. Policyholders approach an insurer so that in return for the payment of premiums, the company accepts the liability to make a monetary payment to them on the occurrence of a specified event within a specified period of time (ManufacturersAssociationofNigeria, 2021).

One of the key ingredients in the definition of an insurance contract is the aspect at which the insurance company undertakes to indemnify or pay a certain amount of money as a compensation to the prospective insured in the case of an unforeseen events which can happened or occur to either the insured and any of his property or his legal liability to a third party in case of any death or bodily injury to them. One of the essences of the existence or main objectives of insurance risk transfer mechanism is in the aspect of claim, which the occurrence of it will on one side be in favor of the insured as fulfilling his expectation in buying an insurance through the benefits he will receive upon the occurrence of the loss or indemnity getting in the case of a non-life policies, which can sometimes not really in favor of the insurance company by reducing their reserves. Claim can otherwise be in favor of the insurance in a situation where it fails to occur during the duration of a policy period which will not make them not to be liable in paying any benefits or indemnifying the insured and hence will help them retain the premium paid by the insured at the inception of the contract and help them in increasing their reserve in form of profit (Wileyand, 2019).

Afsheen and Mohamed(2021) asserts that, payments of claims by insurance companies constitute the main services of insurance to the community if payments are delayed or withheld without any satisfactory reasons, policyholders will quite rightly lose confidence in the insurer concerned or in the industry as a whole, which can lead to the reduction on the rate of their customers and hence reduced the profitability level of such company. Al-Tamimi (2021) submitted that claims from previous years usually surface in succeeding years, which makes the insurance businesses challenging and the attainment of profitability, very difficult.

According to Fan(2021), he opines that, one of the ways in which insurance companies have tried to maintain a competitive edge is by continuously improying their existing business processes. By overhauling existing processes to change with the times, companies can work towards enhanced efficiency, quality, and better response times. But the insurance industry is notably late to incorporating such process improvements, especially Business Process Management (BPM)for insurance in core areas such as underwriting and claims. The insurance industry is one of the most labor-intensive industries out there and is characterized by an increasing amount of work volume which is impossible for the insurance agent to undertake daily while remaining productive.

Niinimaki (2021) is of the opinion that there is a low level of insurance awareness in our society. The public is not properly educated on the scope, function and limitations of insurance transactions especially in the issue that may cause disputes that arise in an insurance contract has to do with the settlement of claims. An important factor that distinguished a good insurance company is its claim settlement services. It does not mean an insurer should be over liberal in order to edge itself out of the market. When the policy has been issued, the risk for the peril insured against is covered. The contingency against which protection is given or not materialized when the loss insured against actually occurs, the insured has got to make a claim on the insurer for indemnification of 
loss and admitted genuine claims should be settled promptly for an insurance company to maintain a good public image.

In achieving a cost reduction in the claim management process and delivering on a value-added brand promise to customers, the focus seems to be effective and efficient managerial process in the claims function. In this regard, claims management process has been a daunting task because of its critical function that touches all aspects of the organization relating to service delivery, exposure to risk, positioning of competitiveness, fraud management and infrastructural development. To some insured's, the belief is that the insurer is only interested in premium collection, and not settlement of claim. Al-Mazrooei(2020) points at certain inefficiencies that adversely affect customer's claims experience to include: aging technology, rising number of fraudulent claims and increasing complexity in the claims processes. However, the increasing difficulties in the claims management processes are rationale for which this study is embarked upon, namely: inappropriateness in claims acknowledgement and assignment; ill-design of information systems to identifying existing claims; communication gap between insurers and customers; claims investigation and documentation time-consuming; insufficient professionalism in the determination of loss situation and amount; and inappropriate conclusion and monitoring of claim handling process.

\section{Objectives of the Study}

1. Determine whether claim handling has effect on profit maximization in an insurance company.

2. Ascertain whether claim's information systems are always well-designed for proper identification of existing policies by insurance companies.

\section{Hypotheses}

$\mathbf{H}_{01}$ : Claim handling has no significant effect on profit maximization of an insurance company.

$\mathbf{H}_{\mathbf{0 2}}$ : Claim's information systems are not always well-designed for proper identification of existing policies by insurance companies.

\section{Literature Review}

\section{Claims and Insurance}

A claim on an insurance policy, according to Anwarul(2020), is a demand on an insurance company to fulfill its portion of the promise, committed to while writing the contract with the insured. Hahm (2020) defined a claim as a demand made by the insured person to the insurer for the payment of benefits under a policy. Khambata and Bagdi (2020) earlier submitted that an insurance claim is also a demand by a person or an organization seeking to recover from an insurer for a loss that an insurance policy might cover. A claim, according to Al-Tamimi and Al-Mazrooei(2019), is described as a notification to an amount is due under the terms of a policy. However, Hussein and Faris (2019) described claim as a defining moment in the relationship between an insurance company and its customer. Similarly, such relationship can become healthy if the insurers are able to address 
five key issues such as: taking greater control of the claim process; understanding their customer; choosing the right claims model for their business; developing a mutually beneficial relationship with other service providers; and gaining an information advantage. Santomero(2019) opines that insurers can transform the claims processing by leveraging modern claims system that are aligned with robust business intelligence, document and content management system that will improve claims processing efficiency and effectiveness. The need to shift from claims handling to efficient claims management has now been recognized by insurers (Wetmore, 2019), as this seems to be fundamental to profit and long-term sustainability of the company, through customer satisfaction, policy renewal and customer retention. According to Sare(2018), an insurer that manages claim will also make effort to minimize cases of fraudulent claims. It is reported by Sare (2018) that $10 \%$ of all insurance claims are fraudulent. Moreover, claim situations should be properly monitored in order to identify recovery opportunities from salvage, subrogation or third parties. Missed recovery opportunities will have considerable implications for the profitability of an insurer. Insurers should also develop the skill and expertise in loss reserving and claims forecasting since this reduces the need for contingent increases of loss reserve. In addition, claims manager should create a balance between avoiding claims delay and reducing loss adjustment expenses. Finally, efforts should be made to minimize litigation expenses. Studies recently conducted in Nigeria among insurance experts within the academia had given quite a number of revelations with respect to insurance fraud; claims handling process; claim cost and insurer' profitability; among others (Sare, 2018; and Khour, 2017). However, Michael (2008) earlier stated that the core elements of a modern claim management system that can process all claim types should include: a component of case management along with the skill to calculating and processing complex reoccurring payments. Krishn and Sunita(2017) opined that for insurers to significantly enhance their claims management and promptly adapting to changing situations, they are required to make more profound infrastructural changes that align claims processing with organization objectives for customer service, operational cost and risk management.

Quite a number of recent studies such as Wang(2017), Afsheen and Mohamed, (2021), had revealed that insurance company's management of claims process is an integral link to its profitability and continuous survival, and also, mentioned that good claim management ought to be proactively conducted in acknowledging and paying claims legitimately; and then, evaluating accurately the claims reserve. According to the Association of Insurance and Risk Managers in Industry and Commerce (2009), paying claims legitimately is a representation of the delivery of the promise at the heart of the insurance contract, which in fact indicate excellent claims handling service that is considered as a differentiator that separate them from their competitors. An excellent claims handling service is an insurance company's competitive edge and thus, noted as a service that customer value greatly. Also, Al-Tamimi (2021) argued that a highly effective claims practice can be a vital contributor to attracting new customers and strengthening customer loyalty to produce a valuable customer experience. According to an earlier remark by the Organization for Economic Co-operation and Development in 2004, a good insurance claim management process should involve: claims reporting; receipt of claims by the company; claims files and procedures; fraud detection and prevention; claims assessment; timely claim process; complaints and dispute settlement; and supervision of claims-related services. 
Often times, situations that arise from loss events awake the insuring populace towards the need for protective measure. However, claims are noted as the most critical channels and a defining link that shape the overall perception of the customers towards their insurer (Fan,2021). According to Niinimaki(2021), the claims processing is the mirror to the customer that enable the insurers' drive at improving customers' acquisition, expectation, retention and business' insight for product enhancement and company's profitability. Therefore, the drive, accuracy, efficiency and effectiveness of claims managerial procedures is key for cost control, risk management and meeting expectation needed for proper portfolio underwriting.

Insurance is the equitable transfer of the risk of loss, from one entity to another in exchange for payment. It is a form of risk management primarily used to hedge against the risk of a contingent, uncertain loss. It involves the pooling of funds from many insured entities (known as exposures) to pay for the losses that some may incur. Insurance as a modern concept for solving risk-related problems depends on the co-operation of a large number of people for its success. Insurance is a safeguard against risk. Any device aimed at reducing the chances of a risk occurring when it happens, reducing the extent of its damage and providing the affected persons with compensation is a form of Insurance (Anwarul,2020). Insurance as a modern concept for solving risk-related problems depends on the cooperation of a large basic fundamental of insurance (Hahm, 2020). Since risk is an unavoidable event in every business venture, there will need to understand events in like manner, there will also need to understand what risk entails for.

\section{Claim Management Process}

Adebiyi(2015) noted that the core challenges driving business costs in claims processing involve: responsiveness; flexibility and management of workflow; supply chain management; and business intelligence. Adewole(2020) argued that the key components that must, be in place in a bid to delivering excellence in insurance claims handling include: culture and philosophy, communication, people, claims management, infrastructure, date management, operations, and monitoring and review. According to Agbamuche(2021), the five steps for optimizing the insurance claims process involve: data organization; analysis and planning; mobility; management and customer engagement. Akingbohungbe(2012) was of the opinion that claims processing involves some tasks such as: following up with the claimant or third party for missing documentation and validating that all required claim information has been collected. It was arguably considered thus that claim managers ought to focus only on the most significant claim tasks that required their attention, and also optimizing the use of their time.

According to Al-Faki(2016), for insurers to attain operational efficiency and effectiveness in claim process, they must look directly at implementing modern claims system; leveraging advanced fraud detection technologies and creating innovation around their self-service claim processing activities. Alile(2012) expressed that those involved in the management of claims seek to achieve: increased efficiency in their claims handling process; improved control over the process with a view to managing and guaranteeing service levels; seamless integration across the end-to-end claims process; greater flexibility within the process to respond to changes within the market; and the ability to deliver this across multiple distribution channels to their customers and partners. Benefits that have been allude to effective claims management process, according to Boon (2017), 
were noted as: improved customer service; reduced indemnity costs, improved claims handling and administration; reduction in allocated loss adjustment expresses; improved operational management; improved enterprise risk management; enhanced business agility; and core brand differentiation. According to an earlier submission by Ekundayo (2012), a good claim management process is expected to include: pro activeness in recognizing and paying legitimate claims; assessing exactly the reserve associated with each claim; reporting regularly; minimizing unnecessary costs; avoiding protracted legit disputation; dealing with claimants carefully; and expediting claims handling. Ewan,Esang, and Bassey(2019) opined that the key areas insurers should take critical look at in achieving operational excellence in claims management are: leveraging advanced analytics, supplier management, legal cost management, technology enablement, and fraud detection. According to Eze and Okoye,(2017), claims process commences at underwriting function which is guided by structured losses experience data. An experiential revelation by Haiss and Sümegi, (2018) noted that in addressing the various challenges in the insurance claims management process, a set of technology-related processing significant to enhancing claim have been identified as follows:

(i) An integrated and flexible architecture;

(ii) Business intelligence enable by more sophisticated data management, analysis and reporting throughout the enterprise;

(iii) Deeper integration of business processes, as well as visibility provided by monitoring, alerts, and reporting;

(iv) Increased collaboration;

(v) Support for mobile workers;

(vi) Cost-effective migration from legacy systems; and

(vii) Industry and technology standards.

Generally, claim management process consist of four important aspects: settling claims, detecting fraud, lowering costs and avoiding litigation (Marijuana,Sandra, \& lime, 2019). According to Mojekwu, Agwuegbo and Olowokudejo (2012), claims payment represents the largest single cost to insurers and 80.0 per cent of all premiums are spent on claims payment and associated handling charges. Hence, Nzotta(2018) opined that claim management includes all managerial decisions and processes concerning the settlement and payment of claims in accordance with the terms of insurance contract.

Rose (2019) submitted that the performance of insurance company in financial terms is normally expressed in net premium earned, profitability from underwriting activities, annual turnover, return on investment and return equity. These can be categorized into profit performance measure and investment performance measure. Profit, according to Sule and Momoh (2019), is important to investors and management as sources of dividends and growth, while to the policyholder, it provides security against insolvency

\section{Research Methodology}

The research method and design adopted for this research work is the survey design method which involves selecting of some insurance companies in Nigeria and in Lagos state specifically, and the data collected is gotten with the use of questionnaire to gather and investigate the behavior phenomenon in the insurance industry 
concerning effects at which the claim handling and occurrence is having on the maximization of profit on the insurance industry.

The targeted study populations are the personnel of Lead Way Assurance PLC.They are divided into three (3) parts namely; low-level, middle-level and top-level employee in insurance industry in Nigeria with a total of 150 questionnaires administered and 120 were retrieved.Ordinary Regression Model was used to test the hypotheses formulated for this study.

\section{Data Analysis and Presentation}

\section{Respondents Characteristics and Classification}

The response given in the questionnaire is used as research instruments and was analyzed with the use of tables and percentages.

Table 1 Questionnaire Administration

\begin{tabular}{|l|c|c|}
\hline CLASSIFICATION & NUMBER & PERCENTAGE \\
\hline Completed & 120 & $80 \%$ \\
\hline Not Returned & 30 & $20 \%$ \\
\hline Total & $\mathbf{1 5 0}$ & $\mathbf{1 0 0 \%}$ \\
\hline
\end{tabular}

Source: Field Survey(2021).

Table 1 above shows that, the total number of questionnaires distributed is 150, and out of it, 120 questionnaires were completed and returned, and 30 questionnaires were unable to be retrieved.

\section{Reliability of the Instrument}

This is whetherthe instrument measure in a consistent and dependable way each time it is utilized under the same condition with the subject.For internal consistency, we used Cronbach's alpha coefficients because it is regarded as a suitable measure of reliability. As could be seen in the table 2 below, all the variables have Cronbach's alpha coefficient above 0.7 . Thus, confirming reliability of the instrument for the study.

Table 2 Reliability test

\begin{tabular}{llc}
\hline Variable & Cronhach alpha & Scale \\
& $(\boldsymbol{\alpha})$ & \\
\hline Claim handling & 0.875 & $1-5$ \\
Profit maximization & 0.807 & $1-5$ \\
Claim's information systems & 0.819 & $1-5$
\end{tabular}

Research Field Work, 2021

Validity Tests of the Study Instruments 
Validity is a critical identity in research construct application. The basic question on the mind of scholars is whether or not the instrument(s) measure accurately what it is meant to measure? Validity is into two content, criterion-based, and construct validity modes. To establish this, the following validity tests were conducted in our pilot study: (i) Face validity (ii) Content, i.e., whether content cover the concept correctly. (iii) Construct (Convergent, i.e., whether common items loaded together and Discriminant, i.e., separate variables dully separated). These are discussed in details

\section{Content Validity}

The instrument (questionnaire) was designed on a 5-point Likert scale (1= not relevant, $2=$ somewhat relevant, $3=$ quite relevant, $4=$ relevant, $5=$ very relevant) to evaluate the relevance and suitability of the measurement items. After developing the instruments, it was issued out to ten (10) experts which include: experts in marketing, practitioners, consultants and psychometrics. Weused expert evaluation to rate the instruments and modified based on their comments. Comments made were incorporated in the final questionnaire. It is beneficial to do so as it enables a researcher to assess its internal consistency, inter-item correlations and factor structure. Table 3 shows the results reflecting Content Validity Index (CVI) for the questionnaire all above 0.7 taken as acceptable basing on Amin.

Table 3 CVI for Questionnaire

\begin{tabular}{lcccccccccccc}
\hline & \multicolumn{1}{c}{ Experts } & & & Mean CVI \\
& \multicolumn{1}{c}{ Variable } & $\mathbf{1}$ & $\mathbf{2}$ & $\mathbf{3}$ & $\mathbf{4}$ & $\mathbf{5}$ & $\mathbf{6}$ & $\mathbf{7}$ & $\mathbf{8}$ & $\mathbf{9}$ & $\mathbf{1 0}$ & \\
\cline { 2 - 12 } & & 1 & 0.7 & 0.9 & 1 & 0.9 & 0.5 & 0.9 & 0.9 & 1 & 1 & $\mathbf{0 . 7 8}$ \\
Claim handling & 0.8 & 0.93 & 0.93 & 0.7 & 0.87 & 0.5 & 0.8 & 0.8 & 0.9 & 0.9 & $\mathbf{0 . 8 1}$ \\
Profit maximization & 1 & 1 & 0 & 1 & 1 & 0.6 & 1 & 1 & 0.8 & 0.9 & $\mathbf{0 . 8 3}$ \\
Claim's information systems & 1 & 1 & &
\end{tabular}

Research Field Work, 2021

Here, two dimensions were employed; Convergent validity (to show items homogeneity within the same construct) and discriminant validity (to indicate heterogeneity between different constructs). These two categories were performed using Exploratory Factor Analysis (EFA).

(a) For convergent validity, we ran EFA and used communalities to confirm this. All items loading was above 0.5 implying that they were highly related to the global variables indicating that convergent validity exists.

(b) For discriminant validity, we ran EFA to show rotated component matrix (see tables in the appendix).

(i) Unrelated items were deleted and loaded separately from each other

(ii) Similar items loaded highly to a single factor

(iii) Based on principal component method, factors with eigen values greater than 1 were retained (GuttmannKaiser rule)

(iv) All our variables had more than one factor i.e., 2-3 confirming discriminant validity

\section{KMO and Bartlett's Sphericity Test}

To evaluate the feasibility of the study, the Kaiser-Meyer-Olkin sampling adequacy index and Bartlett's sphericity test were conducted; both methods suggested the existence of an acceptable inter correlation considering the criteria suggested by scholars. The Maximum extraction method was performed because it best reproduces the population values when the data has normal, multivariate distribution and the statistical 
significance of the extracted factors can be calculated. The results for all the five variables show the KMO values are above 0.7 . This implies that the items in our questionnaire correlate well with other items within their respective clusters to measure the underlying dimension. Hence, adequate to continue with further analysis.

Table 4 KMO and Bartlett's Results

\begin{tabular}{lllllll}
\hline Variable & KMO & \multicolumn{2}{l}{ Bartlett's test } & \multicolumn{2}{c}{ No of factors } \\
& & $\chi^{2}$ & df & Sig & \\
& & 0.934 & 600.823 & 15 & .000 & 2 \\
Claim handling & 0.936 & 898.198 & 21 & .000 & 2 \\
Profit maximization & 0.831 & 5356.774 & 406 & .000 & 3 \\
Claim's information systems & & & & & & \\
\hline
\end{tabular}

Research Field Work, 2021

\section{Test of Hypotheses}

\section{Hypothesis One}

$\mathrm{H}_{01}$ : Claim handling does not have significant effect on profit maximization

Table 5Model Summarybfor Hypothesis One

\begin{tabular}{lrrrrr}
\hline & & & \multicolumn{2}{c}{ Std. Error of the } \\
Model & $\mathrm{R}$ & \multicolumn{1}{c}{ R Square } & Adjusted R Square & \multicolumn{1}{c}{ Estimate } & \multicolumn{1}{c}{ Durbin-Watson } \\
\hline 1 & $.821 \mathrm{a}$ & .767 & .321 & 62141100454.5 & 2.61 \\
\hline
\end{tabular}

a. Predictors: (Constant), Claim handling

b. Dependent Variable: Profit maximization

Source: SPSS version 25 output.

Table 6 Coefficientsafor Hypothesis One

\begin{tabular}{|c|c|c|c|c|c|}
\hline \multirow[b]{3}{*}{ Model } & & & \multicolumn{3}{|l|}{ Standardized } \\
\hline & \multicolumn{2}{|c|}{ Unstandardized Coefficients } & \multicolumn{3}{|l|}{ Coefficients } \\
\hline & B & Std. Error & Beta & $\mathrm{t}$ & Sig. \\
\hline $1 \quad$ (Constant) & 5324132141 & 24141109 & & 3.21 & .004 \\
\hline Claim handling & 5.341 & 2.314 & .761 & 4.32 & .001 \\
\hline
\end{tabular}

a. Dependent Variable: Profit maximization

\section{Source: SPSS version 25 output.}

$\mathrm{R}$ Sqaure explain the relationship between variable. As shown in the model summary, there is positive relationship between Claim handling and profit maximization, and this account for about $82 \%$. $\mathrm{R}$ being the determinant of correlation explain the extent to which the independent variable could explain the dependent variable. $\mathrm{R}$ square as shown in model summary is about $82 \%$, this implies that the independent variables can predict or determine dependent variables up to $82 \%$. This simply means that Claim handling can determine changes in profit maximization up to about $82 \%$. This study revealed that a unit change in Claim handling 
account for about 5.3 positive unit change in profit maximization. This study revealed that Claim handling has significant effect on profit maximization. The $\mathrm{p}$ value of 0.001 is lower than 0.05 , we hereby conclude that Claim handling has significant effect on profit maximization, and hereby reject the null hypothesis.

\section{Hypothesis Two}

$\mathrm{H}_{01}$ : Claim's information systems are not always well-designed for proper identification of existing policies by insurance companies.

Table 7 Model Summarybfor Hypothesis Two

\begin{tabular}{|c|c|c|c|c|}
\hline Model & $\mathrm{R}$ & R Square & Adjusted R Square & $\begin{array}{c}\text { Std. Error of the } \\
\text { Estimate }\end{array}$ \\
\hline 1 & $.786^{\mathrm{a}}$ & .635 & .546 & .15463 \\
\hline
\end{tabular}

a. Predictors: (Constant), Claim's information systems

As shown in the model summary result, the relationship (R-Square) between the dependent and independent variables is about $79 \%$, this implies that the independent variable (Claim's information systems) can predict or determine dependent variable proper identification of existing policies up to $79 \%$.

Table 8 Coefficients for Hypothesis Two

\begin{tabular}{|c|c|c|c|c|c|c|}
\hline \multirow{2}{*}{\multicolumn{2}{|c|}{ Model }} & \multicolumn{2}{|c|}{ Unstandardized Coefficients } & \multirow{2}{*}{$\begin{array}{c}\text { Standardized } \\
\text { Coefficients } \\
\text { Beta }\end{array}$} & \multirow[b]{2}{*}{$\mathrm{t}$} & \multirow[b]{2}{*}{ Sig. } \\
\hline & & B & Std. Error & & & \\
\hline \multirow[t]{4}{*}{1} & (Constant) & 1.554 & 1.312 & & 1.422 & .000 \\
\hline & Claim’s & & & & & \\
\hline & information & 4.950E-5 & .110 & 2.186 & 1.657 & .004 \\
\hline & systems & & & & & \\
\hline
\end{tabular}

a. Dependent Variable: Proper Identification of Existing Policies

The value of the intercept 1.554 is the predicted value of proper identification of existing policies if the independent variable (Claim's information systems) is equal to zero. Claim's information systems have a coefficient value of $\beta_{1}=1.950$; t-test $=0.657$; and $\mathrm{P}=0.004$, this revealed that a positive relationship exists between proper identification of existing policies and claim's information systems. This means that a unit increase in claim's information systems account for about 1.950 unit increase in the proper identification of existing policies. Hence, claim's information systems that are well-designed results to proper identification of existing policies by insurance companies.

\section{Summary}


This paper revealed that claim handling has significant effect on profit maximization of an insurance company; and claim's information systems that are well-designed results to proper identification of existing policies by insurance companies.

\section{Conclusions}

In concluding this study, claim have a great role it playson insurance firm's performance and profit maximization based on the findings and the hypotheses formulated. It is being discovered that, for every insurance to determine their level of profit in any given financial year, claim ratio will always be part of their determinant and profitability and among their priorities. It is being also conclude that, the better performance of both the underwriting and the marketing unit in every insurance company will be determined by the claim record of all the business underwritten or bring in by them respectively. Also, it is being concluded that, for every insurance company looking for ways to maintain or maximize their profitability level, the claim and underwriting unit should be included or recruited with professionals in insurance field with adequate knowledge on what effect the effectiveness of the claim and underwriting can bring to the company's profitability.

\section{Recommendations}

From the research carried out, we have learnt that a proper claim handling can serve as one of the key tools in profit maximization for insurance companies. it will also contribute to their better performance in terms of satisfaction and meeting the organizational objectives. As result of this, some recommendations are presented in this section which could be of interest and help insurance companies, which includes:

1. Claims managers in the Nigerian insurance industry must effectively manage their claims processes, in order to reduce the number of claims for every earned premium.

2. Also, a careful attention must also be given to other administrative cost, such as the underwriting cost, which is capable of reducing the company's profit margin. Future studies can consider the effect of the explanatory variables on other measures of profitability.

3. Nigerian insurance companies should pay special attention to their underwriting process and examine critically the sources and development of new and old businesses.

4. That the industry should disaggregate return distributions across the different classes of insurance so as to ensure competitive strategies.

\section{References}

Adebiyi, M. (2015). Capital market performance and the Nigerian economic growth. Finance and Economic Management Journal, 13(5), 13 - 18.

Adewole, A. (2020). Predicting insurance investment: A factor analytic approach. Journal of Math Science Publication, 6(3), 321 - 324.

Afsheen, S., \& Mohamed, N. (2021). Risk Management Practices Followed by the Manufacturing firms. International Journal of Business and Management Review, 5(1), 144 - 155. 
Agbamuche, U. (2021, April 20). Investment of insurance funds in the Nigerian Capital market. Retrieved from Nigerian Capital Market: www.dare.uva.nl/document/358477

Akingbohungbe, S. (2012). The role of the financial sector in the development of the Nigerian economy. Paper presented at a Workshop Organized by Centre for Africa Law and Development Studies (pp. 46 - 51). Lagos: Centre for Africa Law and Development Studies.

Al-Faki, M. (2016). The Nigerian capital market and socio economic development. Faculty of social sciences publiclecture, University of Benin, 10(3), 9 - 16.

Alile, H. (2012). The nigerian stock exchange: HistoricalPerspectives, operations and contributions to economic development. Central Bank of Nigerian Bullions, 4(2), 65 - 68.

Al-Mazrooei, F. (2020). Implementing Basel II: An Investigation of the UAE Banks' Basel II Preparations. Journal of Financial Regulation and Compliance, 4(2), 177 - 199.

Al-Tamimi, H. (2021). Risk management and performance of manufacturing firms in UAE. Journal of Financial Regulation and Compliance, 16(1), 173 - 187.

Al-Tamimi, H., \& Al-Mazrooei, F. (2019). Banks' Risk Management: A Comparison Study of UAE National and Foreign Banks. Journal of Risk Finance, 17(4), 394 - 409.

Anwarul, M. (2020). An Empirical Study on Risk Management in Some Selected Conventional and Islamic Banks in Nigeria. Beykent University Journal of Social Sciences, 16(10), 1307 - 1344.

Boon, K. (2017). An analysis of Singapore economy. Working Paper of the School of Humanities and Social Studies (pp. 19 - 21). Nanyang: Nanyang Technological University.

Ekundayo, I. (2012). Creating a conducive environment for investment in the Nigerian capital market. Paper Presented at Public Enlightenment on Opportunities in the Capital Market for industrial Development of Kogi state Lokoja (pp. 29 - 35). Kogi State, Lokoja; Kogi State Press.

Ewan, S., Esang, A. E., \& Bassey, J. U. (2019). Appraisal of capital market efficiency on economic growth in Nigeria. Journal of Business and Management, 4(12), 219 - 288.

Eze, O. R., \& Okoye, O. (2017). Analysis of insurance practices and economic growth in Nigeria: Using cointegration test and error correction model. Global Advanced Research Journal of Management and Business Studies, 2(1), 063 - 070.

Fan, L. L. (2021). Efficiency versus risk in the manufacturing firms. Journal of Management Sciences, 4(2), 55 79.

Hahm, J. H. (2020). Effect of risk, high interest rate and exchange rate on manufacturing firms. Applied Economics, 15(11), 1049 - 1061.

Haiss, P., \& Sümegi, K. (2018). The relationship between insurance and economic growth in Europe: A theoretical and empirical analysis. Empirical Journal, 35(4), 405 - 431.

Hussein, A. H., \& Faris, M. A. (2019). Industry's risk management: a comparison study of UAE national and manufacturing firms. Journal of Risk Finance, 8(4), 394 - 409.

Khambata, D., \& Bagdi, R. (2020). Off-balance-sheetcredit risk of the top 20 manufacturing firms. Journal of International Banking Regulation, 5(1), 57 - 71.

Khour, J. P. (2017). Financial risk management domestic and international dimensions. Cambridge, Massachusetts: Blackwell Publishers. 
Krishn, A., \& Sunita, A. (2017). Risk Management in Indian Banks: Some Emerging Issues. International Journal of Economic Review, 14(6), 102 - 109.

Manufacturers-Association-of-Nigeria. (2021, January 16). COVID 19 and closure of manufacturing companies in Nigeria. Retrieved March 24, 2021, from Manufacturers Association of Nigeria: www.man.com

Marijuana, C., Sandra, L., \& lime, P. (2019). Insurance sector development and economic growth in transition countries. International Research Journal of Finance and Economy, 14(8), 34 - 47.

Mojekwu, J., Agwuegbo, S., \& Olowokudejo, F. F. (2012). The impact of insurance contribution on economic growthin Nigeria. Journal of economics and international finance, 3(7), 444 - 451.

Niinimaki, J. P. (2021). The effects of competition of banks risk taking. Journal of Economics, 4(2), 199 - 222.

Nzotta, S. (2018). Money, banking and finance. Owerri: Hudson-Jude Nigeria Publishers.

Rose, P. (2019). Money and capital market. Rexas business Journal of the CIIN, 15(4), 20 - 31.

Santomero, A. (2019). Industry risk management: An analysis of process. Wharton Financial Institutions Center Conference on Risk Management in Banking (pp. 741 - 762). Chicago: ADF Press.

Sare, S. P. (2018). Risk management practices among manufacturing firms. European Journal of Business and Managemen, 5(20), 185 - 191.

Sule, O., \& Momoh, J. (2019). Capital market and the Nigeria industrial growth, financial system and economic growth. Abuja: A CBN publication.

Wang, J. (2017). Return and volatility intra-day transmitting of dually-traded stocks: The case of Taiwan, Korea, Hong Kong and Singapore. Journal of Economics and Management, 2(1), 119 - 141.

Wetmore, J. (2019). Panel data, liquidity risk, and increasing (oans-to-cor deposits ratio of large commercial bank holding companies. American Business Review, 9(2), 99 - 107.

Wileyand, J. (2019). Risk management in manufacturing firms (2nd ed.). Singapore: BNT Publisher. 